\title{
O Corpo Transparente e o Panóptico Expandido: Considerações sobre as Tecnologias de Imagem nas Reconfigurações da Pessoa Contemporânea ${ }^{1}$
}

\author{
LILIAN KRAKOWSKI CHAZAN ${ }^{2}$
}

Este artigo discute como as tecnologias de imagem - em especial as aplicadas à medicina, ao longo do século XX - interagem com a cultura visual, e como, a partir desta articulação dinâmica são reconfigurados - entre outros aspectos - o corpo e a Pessoa. Do mesmo modo que outras atividades humanas, a visualidade é informada e configurada pelo contexto sociocultural e histórico na qual é vivenciada. Nas últimas décadas do século XX, com a difusão da tecnologia computacional, emergem novos paradigmas informados pela digitalização da informação e da imagem. Em conjunto com as tecnologias visuais, outras áreas da ciência, em especial a genética, têm desempenhado papel significativo para novas construções sociais, aqui abordadas de passagem, como tentativa de expor parte da complexa situação na qual ocorrem as reconfigurações do corpo e da Pessoa.

Palavras-chave: Tecnologias de imagem; corpo; Pessoa; cultura visual; digitalização. 


\section{Introdução}

Neste trabalho discutimos basicamente de que modo as tecnologias de imagem - em especial as aplicadas à medicina, ao longo do século XX interagem com a cultura visual contemporânea, e como esta contribui dinamicamente para reconfigurar - entre outros aspectos - o corpo e a Pessoa. Partimos do pressuposto de que, da mesma maneira que outras atividades humanas, a visualidade é informada e configurada pelo contexto sociocultural e histórico na qual é vivenciada. De acordo com diversos autores que investigam a visualidade, no início do século XIX ocorreu uma transformação radical nos códigos de visualidade e na posição ocupada pelo observador.

Em trabalho anterior, discutimos a ruptura epistemológica ocorrida nesse período, no qual se constituíram tanto uma nova visualidade quanto um tipo diferente de observador. A visão, até então concebida como racional e objetiva, passava a ser encarada como um fenômeno basicamente subjetivo, produzido no e pelo indivíduo. Essa modificação se inscrevia no contexto do movimento romântico na Europa, quando se radicalizou a subjetivação do indivíduo e o corpo tornou-se objeto de numerosas pesquisas científicas referentes à natureza, à intensidade e à qualidade das sensações. Configurou-se uma tendência crescente à biologização das sensações, a visual sendo destacada. Foram inventados diversos instrumentos óticos para pesquisas científicas sobre a visão, que rapidamente se tornaram objetos de consumo e lazer. Este fenômeno não apenas reforçava novos códigos de visualidade, como também servia para treinar um outro tipo de atenção, necessária diante dos processos de automação industrial (Chazan, 2001).

A tecnologia foi uma ferramenta essencial nessa transformação: a fotografia, inventada na primeira metade do século XIX, de imediato é utilizada na medicina, para registro e análise dos corpos doentes. No fim do século, a invenção dos raios- $X$ contribui de forma acentuada para novas configurações - tanto do olhar como de conceitos sobre os corpos. O olhar que atravessa os corpos - antes opacos - representa não apenas uma extensão do controle e disciplinarização dos corpos, mas também um reforço da subjetividade ancorada no corpo, em tensão com a razão desprendida cartesiana.

Os estudos científicos sobre o movimento dos corpos, que deram origem ao cinema, inscrevem-se no mesmo processo, no qual são transformados tanto o significado e o valor da imagem na cultura, como o observador e suas práticas visuais. Nessa articulação dinâmica modifica-se e amplia-se o 
valor da imagem para a cultura, dando origem ao que diversos teóricos definiram e vêm analisando como "cultura visual". As pesquisadoras Marita Sturken e Lisa Cartwright a definem como o conjunto de aspectos da cultura que se manifesta de maneira visual, entendendo-se cultura como um processo interativo e não um conjunto fixo de práticas e representações (Sturken \& Cartwright, 2001, p. 4). Essas autoras utilizam uma abordagem analítica fenomenológica da cultura visual, por entenderem que:

\begin{abstract}
"A fenomenologia oferece meios de examinar a distinta materialidade dos meios de produção de imagem em termos de como cada uma afeta diferentemente a experiência do observador e o impacto vivido pelo corpo deste. Dada a necessidade de fundamentar esta diferença material em contextos específicos históricos e políticos, a fenomenologia é mais útil quando utilizada em conjunto com análises sócio-históricas e culturais" (Sturken \& Cartwright, 2001, p. 135) ${ }^{3}$.
\end{abstract}

Em nossos dias, imagens do interior e exterior dos corpos encontram-se presentes quotidianamente no espaço público, veiculadas pelos mais variados media visuais ${ }^{4}$, com os mais diversos propósitos - publicidade, p. ex. Desse contexto de saturação visual com todo tipo de imagens de corpos emerge a indagação se o panóptico (Foucault, 1999) não teria sido invertido, havendo uma soma e uma convergência dos olhares médico e leigo para além da superfície e dos comportamentos, abrangendo-se nesse olhar também as vísceras e o funcionamento fisiológico de cada indivíduo. Desse modo, a imagem técnica de suas entranhas contribuiria de maneira peculiar para sua subjetivação, ao "incorporar" as novas formas de visualização do corpo em sua construção social. Assim, no mesmo movimento, a tecnologia de imagem médica estaria proporcionando uma ampliação da vigilância e controle dos corpos e contribuindo para a construção de novos significados na cultura visual.

A constituição de um tipo específico de subjetividade necessariamente mediada pela tecnologia de imagem contribui para a produção, em áreas diversificadas da cultura contemporânea, de uma espécie de fusão do corpo com a máquina. Em conjunto com as tecnologias visuais, outras disciplinas, em especial a genética, têm desempenhado papel significativo para novas configurações, de modo que não pudemos evitar abordá-las, mesmo que apenas de passagem, como uma tentativa de expor parte do complexo pano de fundo no qual estão inseridas as questões abordadas neste artigo. 


\section{A Cultura Visual e a Tecnologia de Imagem}

No final do século XIX, os centros urbanos e industriais tornaram-se saturados de estímulos sensoriais capazes de produzir acentuada dispersão. Diante da crescente automação da indústria, a desatenção tornou-se perigosa e problemática. A atenção tornou-se foco de grande parte dos estudos de psicologia científica (Crary, 2001, p. 84).

"É possível ver como um aspecto crucial da modernidade uma crise contínua de atenção, ver as configurações variáveis do capitalismo impulsionando a atenção e a distração a novos limites e limiares - com a introdução ininterrupta de novos produtos, novas fontes de estímulo e fluxos de informações -, e em seguida respondendo com novos métodos de administrar e regular a percepção" (Crary, 2001, p. 83).

Esse processo demanda e impulsiona a construção de um novo tipo de atenção visual. Durante esse período, há inúmeras pesquisas buscando compreender cientificamente a natureza das sensações, a visão ocupando posição privilegiada. Desse modo, o olhar compatibilizava-se com outros processos de modernização, que criavam incessantemente uma nova produção, um novo consumo e novas necessidades (Crary, 2001, p. 82).

Em outras pesquisas conseguiu-se localizar funções dos nervos e do cérebro e estabeleceu-se a distinção entre funções motoras e perceptivas, produzindo-se novas verdades sobre o corpo. Estes estudos constroem uma noção diferente acerca da separação dos sentidos, sustentada principalmente pelas investigações de Johannes Müller, fisiologista alemão, autor da primeira grande teorização científica sobre o assunto. Sua contribuição foi decisiva para a ruptura com a noção de observador vigente na era clássica: suas pesquisas demonstraram que os nervos dos cinco sentidos eram distintos entre si fisiologicamente e que, dependendo do tipo de nervo estimulado, causas uniformes geravam sensações diferenciadas. Demonstrou também que diferentes tipos de estimulação de um mesmo nervo provocavam a mesma sensação. Evidenciava-se assim uma relação arbitrária entre estímulo e sensação: p.ex., a sensação da luz, para o observador, não tinha nenhuma conexão com o fenômeno físico da luz (Crary, 1999a, p. 36). Um mundo real novo é construído sobre a ausência de referenciais fixos: a natureza empírica daquele que percebe torna as identidades instáveis e móveis. O destacamento entre representação mental e seu referente ${ }^{5}$ material estabelece um precedente que será examinado mais adiante. Crary observa: 
“(...) a doutrina da energia específica dos nervos redefine a visão como uma capacidade de ser afetado por sensações que não estão necessariamente ligadas a algo concreto, ameaçando desta maneira qualquer sistema coerente de significados (...)" (Crary, 1999a, p. 40).

Diversos artefatos óticos desenvolvidos por pesquisadores nesse período, visando a estudos científicos, rapidamente foram transformados em objetos de diversão (Crary, 1999b, p. 97) ${ }^{6}$. Essa forma de entretenimento contribuía de maneira marcante para a construção de um novo tipo de atenção e treinamento visual, assim como para a consolidação das imagens e da atividade visual como elementos geradores de prazer. Um desses aparelhos óticos, o estereoscópio ${ }^{7}$, produzia um efeito de tangibilidade aparente dos objetos, como uma experiência exclusivamente visual. A noção de profundidade obtida era bem diferente da que se poderia observar em uma pintura ou, depois, na fotografia. Os elementos individuais apareciam como objetos planos, recortados, mais perto ou mais longe, a distância entre os objetos como uma noção instável.

Segundo alguns pesquisadores de história da arte e de cultura visual, o estereoscópio rompia com o conceito de espaço contínuo da perspectiva, um dos pilares da construção dos códigos visuais da cultura ocidental desde o Renascimento. Essa ruptura ocorria dentro de um novo paradigma, em tensão com a visão cartesiana de espaço $^{8}$. A desconstrução do espaço da perspectiva estabelece bases para a fragmentação visual que se cristaliza na cultura visual modernista, em especial no cubismo (Crary, 1999a, 1999b, 2001; Cartwright, 1995).

Com o avanço dos processos de automação industrial, a codificação, quantificação e otimização dos movimentos corporais - em especial dos trabalhadores nas fábricas - adquirem importância inédita, estimulando a produção de vários estudos científicos sobre os movimentos corporais de seres humanos e animais. Estabelece-se aos poucos uma configuração cultural na qual a visualidade desempenha papel central. Evidencia-se o quanto o processo de disciplinarização crescente alimenta as pesquisas em tecnologias de imagem que, ao serem transformadas em entretenimento, passam a ter papel relevante na construção de uma cultura que se torna cada vez mais visual e pervasiva, ancorada em imagens técnicas de toda ordem.

No início do século XX, utilizou-se a técnica cinematográfica acoplada ao microscópio, produzindo-se filmes que visavam à análise dos aspectos diminutos do interior do organismo. Contudo, para a produção desse tipo de 
imagem, era tecnicamente necessário reduzir o objeto da observação à bidimensionalidade, pois caso contrário seria impossível obter imagem microscópica ${ }^{9}$. Colocava-se o problema de como registrar e analisar o corpo vivo, se este era tridimensional. A técnica produzida para a obtenção desse tipo de imagem - inserindo um aparelho na orelha de um coelho vivo, o que possibilitava a visualização microscópica da circulação sangüínea - transformava concretamente o corpo em "parte de um sistema vivo que incorpora as tecnologias de sua representação" (Cartwright, 1995, p. xiv) ${ }^{10}$.

A imagem da célula é uma imagem técnica produzida que não tem um referente no mundo real. Portanto, ela só existe na cultura como uma representação abstrata, obtida por via das lentes do microscópio. Essa visualização contribui para a construção de novos códigos visuais no tocante ao organismo e, em última instância, à vida. Abre-se então uma dupla perspectiva para a construção social do corpo: por um lado, "ultra-objetiva", "concreta", visualizada nos mínimos detalhes; por outro, "pura" imagem, abstração total - de certo modo, "hiper-real", nos termos de Baudrillard" ${ }^{11}$.

\section{Imagem Técnica na Medicina, Raios-X e Corpo "Transparente"}

A natureza mecânica da produção de imagens técnicas contém o legado do paradigma positivista no qual a fotografia foi gerada. As imagens estiveram presentes nos discursos e na prática científica desde muito antes da fotografia (Sturken \& Cartwright, 2001, p. 281) ${ }^{12}$. Pouco após seu surgimento, a fotografia foi largamente utilizada nos estudos médicos e de outras disciplinas, como a antropologia, sendo considerada uma técnica perfeita para registro de aspectos anatômicos e morfológicos do corpo humano (Sturken \& Cartwright, 2001, p. 284). Usou-se fotografia para catalogar tipos físicos, doenças e para identificar cidadãos no século XIX, a imagem estática destacada do indivíduo permitindo um perscrutamento mais detalhado. A utilização científica da fotografia inscreve-se num contexto no qual as teorias de degeneração encontravam-se em pleno vigor, de modo que essa técnica fornece munição para extensas argumentações objetivas sobre a diferença.

A frenologia, popular entre 1820 e 1850 , e, mais tarde, a craniologia, partiam do pressuposto de que o aspecto físico era indiciário do desenvolvimento moral e intelectual (Sturken \& Cartwright, 2001, p. 281). A fisiognomia - interpretação da configuração do corpo, especialmente face -, motivo de interesse desde longa data ${ }^{13}$, ganha novo impulso com a fotografia (Sturken \& Cartwright, 2001, p. 282). Na Salpêtrière, Charcot e 
o fotógrafo Albert Londe documentaram crises histéricas em fotografias seqüenciais, elaborando alguns estudos visuais que reconstituíam o movimento corporal dos pacientes em crise. Para Charcot, a observação forneceria a chave para o entendimento de diversas doenças, e a fotografia seria o meio ideal na ampliação da capacidade de observação (Sturken \& Cartwright, 2001, p. 284).

De acordo com Foucault (1998), a ruptura fundamental na história da medicina ocidental ocorreu quando a experiência clínica se transformou em olhar anátomo-clínico. No final do século XVIII, instaura-se na medicina a soberania do olhar. O método clínico articula-se com a emergência de um olhar médico que unifica signo e sintoma em um significante de doença, tornando-se o significado. Para que o olhar clínico estabelecesse uma conexão com a anatomia patológica, foi necessário haver uma reorganização de ambos. O olhar médico precisa percorrer um caminho vertical, indo da superfície sintomática até a profundidade dos tecidos, e daí de volta para o sintoma, correlacionando as duas superfícies: a sintomática e a tissular. Estabelece-se desse modo uma terceira dimensão e articula-se a experiência anátomo-clínica, na qual o olhar médico deverá ver a doença ao mesmo tempo em que penetra no corpo do doente (Foucault, 1998, p. 167). Essa conexão entre o pensamento clínico e as patologias que acometem o corpo vivo contribui para a construção de um campo favorável ao desenvolvimento de tecnologias que permitam observá-lo de forma cada vez mais acurada e penetrante, ampliando as possibilidades de controle sobre os corpos vivos.

Em fins de 1895, na Alemanha, W. K. Röentgen produz pela primeira vez os raios-X $(\mathrm{RX})$, em um experimento com raios catódicos em seu laboratório $^{14}$. O novo tipo de raio luminoso é rapidamente apropriado para uso em medicina e, no início de 1896, é realizada a primeira radiografia, da mão de Bertha Röentgen (Porter, 1997, p. 605). Cartwright aponta uma ambigüidade nas primeiras imagens proporcionadas pelos RX: o registro radiográfico do interior do corpo vivo apresenta um esqueleto - figura icônica da morte (Cartwright, 1995, p. 121). A produção de um tipo de raio luminoso, invisível na claridade, que devassava corpos e produzia imagens gerou uma reação ruidosa no público ${ }^{15}$. As imagens radiográficas funcionaram, na época, ao mesmo tempo como "ícones, fetiches e artefatos de saúde, vida, sexualidade e - mais significativamente - de morte" (Cartwright, 1995, p. 107).

Segundo Cartwright, o motivo real do escândalo consistia, contudo, no fato de que estava em jogo o texto cultural inscrito na superfície do corpo, pois as primeiras imagens radiográficas aboliam, dentre outros aspectos, a 
identidade sexual, por não evidenciarem a genitália e a musculatura. Desse modo, códigos há muito utilizados para o estabelecimento de identidades estavam sendo ameaçados (Cartwright, 1995, p. 117-119). A produção de um olhar que literalmente atravessa sujeitos contribui decisivamente na reconfiguração do corpo. Constitui possibilidade de dissecação exclusivamente pelo olhar.

Ao mesmo tempo em que a imagem radiográfica privilegia a visão para o estabelecimento de diagnósticos, em detrimento de outros recursos utilizados na semiologia médica ${ }^{16}$, o corpo tornado transparente também não é mais o mesmo. De acordo com Cartwright, o público leigo percebeu de modo claro que os RX eram um modo radicalmente novo de ver e organizar o corpo e tentou se apropriar deste novo olhar (Cartwright, 1995, p. 121). Simultaneamente, consolidava-se a noção de que a tecnologia possibilita descobrir verdades não acessíveis ao olho humano "puro". O ponto mais relevante no tocante à presente discussão é que, através do uso em larga escala das imagens técnicas, de forma ampla e disseminada pela sociedade, reforçava-se a noção da importância das evidências empíricas, que passaram a ser entendidas nas sociedades industrializadas como sinônimo de imagens produzidas pela tecnologia (Sturken \& Cartwright, 2001, p. 285).

A tecnologia visual emerge como um novo poder - altamente complexo e de compreensão inacessível pelo público leigo -, produtor de saberes sobre o corpo radicalmente distintos dos existentes até então. A invenção dos RX se insere nesse campo epistemológico: a visão do interior do corpo por meio de raios invisíveis carreia em seu bojo, ao mesmo tempo, uma "superobjetividade" e um sentido fantasmagórico, mágico.

O termo fantasmagoria ${ }^{17}$ foi utilizado por Theodor Adorno e Walter Benjamin para descrever formas de representação surgidas depois de 1850, que ainda vigoram nos dias atuais. Para Adorno, a fantasmagoria significava “(...) o ocultamento da produção por meio da aparência externa do produto (...) esta aparência externa pode reivindicar o status de ser (...)" (Adorno apud Crary, 1999b, p. 132).

A letra " $X$ " usada para nomear o raio luminoso produzido por Röentgen deveu-se ao fato de ser uma radiação desconhecida. Na produção de imagens radiográficas coloca-se uma questão peculiar concernente à fantasmagoria e, portanto, ao poder intrínseco contido nesta ocultação. A fotografia consistia em um registro, sobre uma emulsão específica, de intensidades variáveis de um tipo de radiação luminosa visível: a luz comum. No tocante aos RX, o registro de sua existência se dá única e exclusivamente 
pela produção da imagem de um corpo atravessado pela radiação, sobre a emulsão fotográfica. Assim como ocorrera com as imagens microscópicas, a única prova da existência dos RX era a imagem produzida na emulsão fotográfica.

Os RX eram representados, nos primeiros anos após sua "descoberta", como uma "força natural que tinha que ser controlada e domesticada para dela se fazer bom uso" (Cartwright, 1995, p. 110). Cartwright chama a atenção para o fato de que a descoberta de Röentgen, na realidade, consistiu na invenção de uma técnica de produção de imagens, e não na "descoberta de uma força natural", conforme foi referida freqüentemente nos primeiros anos (Cartwright, 1995, p. 111). A idéia corrente de descoberta de uma força natural oculta, ao invés da noção de uma radiação produzida em laboratório, contribui para a atribuição do caráter fantasmagórico aos RX. O cientificismo do final do século XIX encontrava-se aqui fundido com o incitamento à imaginação. Os estudos iniciais de Röentgen foram cercados de segredo, pois ele temia que, ao trazer a público as imagens obtidas com RX mostrando o esqueleto, símbolo de morte, sua boa reputação no meio científico fosse abalada (Cartwright, 1995, p. 114).

O corpo "transparente" representa uma mudança qualitativa no tocante à construção social do corpo humano e emergem vários paradoxos: o interior do corpo torna-se "público"; a imagem radiográfica do corpo vivo é um ícone da morte; o devassamento do interior é altamente erotizado e ao mesmo tempo as imagens radiográficas carecem de indicações sobre o sexo do sujeito: as eventuais indicações sobre o gênero estão presentes na radiografia só quando existem objetos radiopacos, como brincos, anéis. A noção de transparência também é reconfigurada, uma vez que essa nova transparência - impregnada da opacidade do corpo - é bem diversa da vigente no modelo clássico de visualidade, da camera obscura ${ }^{18}$.

Durante as primeiras décadas do século XX, com a introdução do escaneamento pulmonar em massa, na saúde pública, visando ao controle da tuberculose, fez-se necessária uma modificação na representação dos RX na cultura leiga ${ }^{19}$. Esta mudança foi construída por meio de grandes campanhas veiculadas pelo cinema: passou-se de um ícone da morte para um ícone de saúde. Padrões sexuais e raciais de beleza, inscritos na superfície do corpo, são transferidos para padrões de qualidade interior: o estado de saúde dos pulmões e do esqueleto. A imagem radiográfica codificada como morte adquire o significado oposto, como modelo normativo de um corpo saudável (Cartwright, 1995, p. 155). 
A onisciência da ciência - materializada nas novas tecnologias que dissecam o corpo pelo olhar - reconfigura e reforça a interioridade concreta dos indivíduos, acrescentando a ela a manutenção do bom estado de saúde como um valor moral. Grande parte das campanhas de divulgação do controle da tuberculose por escaneamento torácico era dirigida às mulheres, e funcionava em registro duplo: por um lado, a mulher era valorizada como um agente de saúde na família; por outro, caso não se engajasse na campanha, tornava-se uma ameaça secreta à saúde da sociedade (Cartwright, 1995, p. 146). A transparência do corpo, entre outras finalidades, respondia também pela manutenção de uma determinada ordem social, através da vigilância sobre o interior dos corpos.

\section{Estudos do Movimento e Controle dos Corpos}

Ao longo do século XIX, o corpo tornou-se gradualmente objeto de escrutínio mais detalhado com a utilização da imagem técnica, em diferentes abordagens: em seus aspectos exteriores, interiores e de relações espaciais. No tocante aos aspectos exteriores, foi registrado pela fotografia que, impregnada em suas origens pelo paradigma positivista, produzia sobre ele "verdades objetivas". Os aspectos interiores do corpo foram devassados, de um ponto de vista literal, com os RX. As relações espaciais foram exploradas nos estudos fotográficos científicos de corpos em movimento, que vieram a dar origem, adiante, ao cinema.

As primeiras técnicas para registro do movimento surgiram estreitamente vinculadas às pesquisas da biologia e da fisiologia - duas disciplinas surgidas no século XIX, voltadas para o estudo da "vida"20. A correlação entre estudos de movimento e a busca de compreensão do fenômeno da vida pela imagem dinâmica torna-se tangível na pessoa de Auguste Lumière, um dos inventores do cinematógrafo, que esteve, ao longo de sua vida, profundamente comprometido com a biologia médica, fisiologia experimental e farmacologia (Cartwright, 1995, p. 1).

De acordo com Cartwright, o aparelho para registro do movimento foi fundamental para a emergência de um novo conjunto de técnicas visuais para controle e regulação social; o olhar anátomo-clínico, empírico e qualitativo, do século XVIII e início do XIX, descrito por Foucault,

“(...) superpõe-se e é ao mesmo tempo desafiado pelo olhar incansavelmente analítico e quantitativo [da Ciência do século XIX](...) [Constitui] um modo 
de percepção (...) incubado nos laboratórios dos fisiologistas e cientistas médicos, que encontra sua expressão em uma mescla (...) de instituições e práticas, incluindo o hospital, o cinema popular, o experimento científico e a produção artística modernista." (Cartwright, 1995, p. xiii).

Para essa autora, o surgimento do cinema, no final do século XIX, correspondeu ao mesmo tempo a "uma instituição e um instrumento para monitoramento, regulação e (...) construção da 'vida', na cultura modernista da ciência médica ocidental” (Cartwright, 1995, p. xi). O cinematógrafo de Lumière e os RX vieram a público no mesmo ano e apresentaram ligações concretas: os irmãos Lumière, assim como Edison ${ }^{21}$, realizaram experimentos com emulsões sensíveis aos RX logo após Röentgen apresentar seu trabalho em público (Cartwright, 1995, p. 109). Foram produzidos filmes em $\mathrm{RX}$ que de certa forma reconstruíam as superfícies tridimensionais anteriormente descartadas na radiografia estática, por evidenciarem o interior do corpo humano, em movimento (Cartwright, 1995, p. 108).

A invenção de diversas tecnologias visuais evidencia uma acentuação no processo de devassar e controlar o indivíduo e no mesmo movimento é reiterada, por meio da visualização tecnológica, a existência do interior do corpo e sua singularidade. Contudo, esse processo de reforço de interioridade se dá sustentado por uma externalização do interior do corpo: os RX trazem um aspecto privado do corpo - os órgãos internos e seu estado de saúde para a visualização pública (Cartwright, 1995, p. 152). Assim, pode-se pensar nessa exposição como uma reafirmação concreta da existência de um interior.

Através da visualização proporcionada pela imagem técnica médica, evidencia-se um aspecto constitutivo da Pessoa na sociedade contemporânea: o indivíduo pode, e eventualmente, deve (como nas campanhas de escaneamento torácico) ser escrutinado, estudado e normatizado, ao mesmo tempo em que se reforçam sua especificidade, singularidade e interioridade. Constrói-se assim um novo sujeito, que tem a percepção de si mesmo reconfigurada, ao incorporar culturalmente a imagem do interior de seu organismo ${ }^{22}$. O novo olhar perscrutante acarreta transformações dramáticas na prática médica, assim como na cultura visual. A imagem técnica tornase importante instrumento para a produção de verdades, via tecnologia, sobre esse indivíduo, incorporando-se - no duplo sentido do termo - na construção do corpo. 


\section{Digitalização da Imagem e Concepções de Corpo e Pessoa}

O interesse pelo interior do corpo permeia a história da medicina ocidental. As tecnologias visuais foram adotadas pela ciência e, por seu turno, reconfiguraram o corpo, tanto em termos estritamente médicos quanto na cultura em geral. Nas últimas décadas do século XX, diversas tecnologias de imagem médica foram inventadas. A tecnologia digital ${ }^{23}$, utilizada na medicina (tomografia computadorizada [CT], ressonância magnética [MRI], PET $^{24}$ scan), sobrepôs-se à analógica ${ }^{25}$, em uma inflexão no mínimo curiosa: para se obter uma imagem mais fidedigna ou mais natural do corpo, os dados precisam passar por um algoritmo computacional notavelmente complexo. A imagem mais real do corpo é também, simultaneamente, mais artificial.

Uma digressão faz-se necessária neste ponto. A digitalização - que se ampliou de maneira pervasiva, abrangendo inúmeras áreas do cotidiano das sociedades modernas urbanas industrializadas - evidencia-se social e culturalmente com a construção de um entendimento peculiar do corpo, sendo o Projeto Genoma Humano uma das traduções possíveis. A idéia de um mapa contendo informações sobre o corpo e seu futuro corresponde de maneira exata à de um corpo digitalizado. $\mathrm{O}$ conhecimento de uma verdade do corpo passa pelo conhecimento das informações contidas nos genes, não mais apenas escrutinado visualmente (Sturken \& Cartwright, 2001, p. 301).

A ciência genética ocupa-se tanto com a identificação quanto com a localização dos genes que compõem o cromossoma humano, muitos deles ligados a doenças e à aparência física. Neste particular há uma semelhança evidente com as práticas de medições físicas que embasaram teorias raciais diversas. As diferenças anteriormente inscritas na superfície dos corpos passam a estar ocultas, codificadas nos genes, existindo uma utilidade potencial no mapeamento genético para o estabelecimento de normas.

Para Sturken e Cartwright, a genética surge na cultura como um novo marcador da diferença biológica e cultural, profundamente problemático. Ideologias discriminatórias sempre se basearam em práticas visuais, através de identificações e classificações do visível. A idéia de um marcador invisível, como o código genético, aparenta ser mais fixada e factual, fora do campo do discurso e do contexto histórico e social (Sturken \& Cartwright, 2001, p. 302). As diferenças seriam imutáveis, a menos que submetidas a terapias genéticas - por enquanto incipientes -, reforçando-se a idéia de que a socialização não é responsável nem efetiva na mudança de comportamen- 
tos, habilidades ou características psicológicas. A genética é percebida como um campo separado, independente e auto-suficiente. De acordo com essas autoras, o mapeamento genético humano foi aceito com entusiasmo na cultura médica e leiga, em parte por construir socialmente o corpo como um mapa digital acessível e decifrável (Sturken \& Cartwright, 2001, p. 301). Assim, reforça-se o lugar da ciência na cultura como um poder confiável e reconfortante: no futuro as doenças poderão ser resolvidas na origem.

De acordo com Sturken e Cartwright, o mapeamento genético constrói socialmente o corpo como se este fosse constituído por um conjunto de bits. Por outro lado, as tecnologias de imagem digital transformam o corpo em algo plástico e mutável. A técnica de morphing - animação computadorizada que fusiona um corpo em outro - ultrapassa as barreiras externas das identidades inscritas nos e entre os corpos, não mais entidades invioláveis. Pode-se gerar a imagem de um corpo composto apenas por bits contendo informações referentes a diversos corpos. A computação gráfica permite a criação, através de programas computacionais, de uma Pessoa virtual, sem referente algum no mundo real. Um exemplo é o envelhecimento virtual gerado a partir de fotos de pessoas jovens. Este procedimento possibilita a localização de sujeitos, anos após desaparecidos, mostrando como seria sua imagem atualizada. É aplicada para encontrar criminosos, muito tempo depois de terem sido fichados pela técnica tradicional dos mug shots (Sturken \& Cartwright, 2001, p. 306) ${ }^{26}$.

As técnicas contemporâneas de imagem, como morphing e realidade virtual, indicam tanto a construção de um corpo mutante, digital e digitalizável, como uma fusão (ou confusão) entre corpo e tecnologia, uma cyborgização que parece tornar fluida a fronteira entre o biológico e o tecnológico (Sturken \& Cartwright, 2001, p. 307).

Exemplo significativo é fornecido pela ultra-sonografia aplicada à obstetrícia. Até meados da década de 1980 a ultra-sonografia obstétrica era um exame caro, pouco acessível e destinado ao acompanhamento de gestações que fossem problemáticas do ponto de vista médico. Em nossos dias, o exame parece ter-se transformado em um novo rito de passagem, tanto para a gestante como para o feto, que, ao ser visto na tela do monitor, passa a ser incluído na moderna sociedade industrial. Produz-se o primeiro retrato da futura criança.

Pesquisadores de cultura visual e médicos concordam que a imagem da ultra-sonografia está impregnada de um sentido de realidade equivalente ao da fotografia, contribuindo de modo relevante para uma antecipação da 
existência social do feto, transformado em Pessoa. A ultra-sonografia fetal, muito mais do que outras tecnologias de imagem médica, adquiriu um significado cultural similar ao da foto de família e dos vídeos caseiros (Sturken \& Cartwright, 2001, p. 294).

Imagens de ultra-som fetal foram apropriadas pela publicidade, como num anúncio da Volvo, em 1996, no qual havia em grande destaque a ultrasonografia de um feto, com a seguinte legenda: "Há algo dentro de você dizendo para comprar um Volvo?". No texto, situado à esquerda de uma pequena foto de um carro, em caracteres bem menores apelava-se para o desejo de proteger o feto, construindo um paralelo entre segurança automobilística e segurança uterina, ao mesmo tempo produzindo e manipulando uma possível ansiedade acerca da capacidade de o corpo feminino apenas, sem outro recurso, ser capaz de proteger e prover bem-estar para o feto (Sturken \& Cartwright, 2001, p. 292). A imagem desse feto, associada ao texto, transforma-o precocemente em consumidor. O feto, neste caso, é explicitamente equiparado a um ser racional que faz opções e dá sugestões, singularizando-se por suas "preferências" automobilísticas. A credibilidade dessa construção é sustentada pelo status de verdade da imagem técnica ultra-sonográfica apresentada no anúncio.

\section{O Panóptico Expandido, Reconfigurações da Pessoa}

Atualmente vivemos cercados por imagens técnicas de toda ordem. Desde o final do século XIX, a visualidade passou a ocupar lugar de destaque na relação do sujeito com o mundo, seja como uma forma de sociabilidade articulada com o crescente afastamento dos corpos no decorrer do processo civilizador, apontado por Elias (1994, p. 200), seja como uma forma socialmente valorizada de prazer, com a indústria de entretenimento. Para Sturken e Cartwright, as imagens técnicas simultaneamente "exercem poder e são instrumentos de poder" (Sturken \& Cartwright, 2001, p. 93). Neste processo de valorização das práticas visuais, as imagens técnicas ocupam locus essencial, pela possibilidade ampliada de circulação de imagens. Em uma via de mão dupla, a tecnologia produz formas mais eficazes de produzir e divulgar imagens, e novos paradigmas emergem, realimentando a cultura produtora de tais tecnologias. Como exemplo, o desafio às noções de original e cópia, tão caras à tradição artística ocidental. A digitalização da imagem (sua transformação em informação matemática) implica intrinsecamente a possibilidade imediata de recomposição, manipulação e repetição. As ima- 
gens digitais contêm, portanto, por princípio, o significado de que podem ser instantaneamente replicadas e infinitamente repetidas - e não copiadas, como ocorre nos processos analógicos.

A sociedade contemporânea, atrelada ao consumo contínuo de mercadorias, depende, para sua manutenção, da constante produção e consumo de bens. As imagens são centrais para a cultura de consumo, e a publicidade visual apresenta quotidianamente o que deve ser desejado, como a vida deveria ser e quais pessoas devem ser invejadas ${ }^{27}$.

Dois dos elementos-chave da publicidade são o estabelecimento de um padrão ótimo de beleza e de satisfação, e a idéia de que o consumidor poderá se transformar neste indivíduo padrão de beleza, de bem-estar ou de sucesso, adquirindo e utilizando os produtos veiculados pela publicidade. Sturken e Cartwright apontam que esta freqüentemente "fala na linguagem do futuro" (Sturken \& Cartwright, 2001, p. 189). Nesse constructo encontra-se implícita a valorização cultural do futuro, por meio da elaboração e apresentação de imagens ideais na publicidade, que poderão ser alcançadas pelo observador. A idéia de um constante aprimoramento de si, via consumo, evidencia-se de modo insistente.

Dessa maneira, através de um processo bastante complexo, é estabelecido o futuro como uma promessa e um valor nas sociedades de consumo. Um ponto relevante para a presente discussão consiste nesta construção de futuro como um valor com caráter moral: "ser atrasado" transforma-se em anátema nas sociedades industrializadas contemporâneas. Articulando estes aspectos, torna-se possível compreender porque e como a imagem técnica em geral torna-se altamente valorizada: ela está intrinsecamente impregnada de um sentido vanguardista de futuro, tão caro à cultura de consumo vigente. A valorização do moderno colore de modo marcante as práticas na biomedicina e, em conjunto com a ênfase atribuída à visualidade na sociedade contemporânea, as diversas tecnologias de imagem médica passam a deter lugar privilegiado na construção de noções médicas e leigas acerca do corpo.

Corpos modernos são conhecidos e configurados por uma tecnologia igualmente moderna. O corpo moderno é um corpo valorizado, foco e fonte do prazer de olhar. O prazer em olhar e em ser visto é constantemente alimentado por novas tecnologias visuais. Todos olham para todos e, expandindo-se este olhar, devassa-se também o interior dos corpos.

Pensando-se na metáfora do panóptico como um olho cuja vigilância por sua invisibilidade - é constante, cabe a consideração de que as tecnologias visuais, médicas e não-médicas, constituem na atualidade um dos importan- 
tes meios do biopoder no gerenciamento da vida. A difusão e o constante desenvolvimento de tecnologias visuais de toda ordem permite-nos pensar, remetendo à hipótese levantada inicialmente, que o panóptico, ao invés de ter sido invertido - todos os olhares convergindo para o interior do corpo e seus processos de subjetivação - parece ter-se expandido em todas as direções, perscrutando simultaneamente todos os corpos, interior e exteriormente. Teria ocorrido, de certa forma, uma espécie de replicação digital do panóptico, infinita e simultânea. No mesmo movimento em que é construído esse novo tipo de corpo e de Pessoa, tão devassáveis pelo olhar, reforça-se o biopoder. Neste processo, não apenas a vigilância constante é essencial - um panopticismo disseminado, por assim dizer -, como também a visualidade e a veiculação de imagens exercem relevante papel constitutivo e normativo.

Nessa normatização, a publicidade contribui de modo significativo, com a produção sempre renovada de padrões de beleza e adequação na sociedade de consumo. No mesmo processo, as tecnologias de imagem médica atuam em duplo sentido: tanto estabelecem normas e padrões de saúde baseados na visualização dos órgãos internos, quanto se reafirmam elas próprias como as principais produtoras de verdades - médicas e leigas - sobre o interior do corpo. Nesse quadro, estabelece-se uma ligação estreita entre imagem técnica e a construção social dos corpos, que são reconfigurados, passando a ser constituídos também por suas imagens técnicas, tanto externas como internas.

A tecnologia ocupa portanto lugar estratégico nesse processo, sendo uma das principais vias de produção desse corpo totalmente vigiado e reconfigurado. Desse modo, o corpo e a Pessoa também são remodelados, mantendo vínculos bastante peculiares com a tecnologia, dentro de uma vasta gama de possibilidades, dentre as quais citamos algumas. Em uma das extremidades desta gama, encontra-se a criação de Pessoas virtuais através de programas computacionais, sem referente algum no mundo real; em outros termos, "Pessoas sem corpo".

Tal possibilidade necessariamente reconfigura a noção de Pessoa, tão profundamente ancorada no próprio corpo na sociedade ocidental contemporânea. No outro extremo, tecnologias de imagem médica, tais como a ressonância magnética (MRI), contribuem decisivamente para objetificar e fragmentar o corpo, destacando-o do sujeito da experiência. A verdade sobre a saúde e a doença do sujeito não se encontra mais no relato da experiência vivida de sofrimento, mas nas imagens produzidas do interior de seu corpo, como se se tratasse de "corpos sem Pessoa". 
O PET scan representa ainda outra inflexão: a idéia de que o funcionamento mental pode ser visto e, mais ainda, mapeado, vincula-se tanto à emulação da tecnologia como a produtora preferencial de verdades sobre o corpo, quanto à ancoragem concreta da subjetividade no corpo, mais especificamente no cérebro, este sendo a Pessoa $^{28}$. Para acrescentar mais combustível à presente discussão, coloca-se contemporaneamente outra vertente, não diretamente vinculada à visualidade e, mesmo, eventualmente contraposta a ela: a noção de digital que, replicada sobre a Pessoa, constrói a idéia de que a identidade (e a identificação) desta poderia ser reduzida às informações contidas em seus genes. A ficção científica - a tradução popular da noção de ciência - trabalha já há algum tempo com estes conceitos ${ }^{29}$.

As tecnologias visuais, médicas e não-médicas, possibilitam visões do corpo que se incorporam na cultura visual, contribuindo para fortalecer a noção de que o corpo não é mais o destino do indivíduo, podendo ser modificado ao bel-prazer de seu dono. A engenharia genética reforça de modo marcante essa idéia. Na atualidade, o comentário de que "tudo que é sólido se desmancha no ar" parece ter passado a incluir também o corpo humano, suas possibilidades e limites.

\section{Referências Bibliográficas}

CAMPBELL, C. A ética romântica e o espírito do consumismo moderno. 1.ed. Rio de Janeiro: Rocco, 2001.

CARTWRIGHT, L. Screening the body: tracing medicine's visual culture. 1.ed. London : University of Minnesota Press, 1995.

CHAZAN, L. K. Fetos, máquinas e subjetividade: um estudo sobre a construção social do feto como pessoa através da tecnologia de imagem. 2000. 116f. Dissertação (Mestrado em Saúde Coletiva) - Instituto de Medicina Social, Universidade do Estado do Rio de Janeiro, 2000.

Camera obscura, estereoscópio, raios-X e outras máquinas: um estudo sobre tecnologias visuais na medicina e a construção da pessoa contemporânea". In: FÓRUM DE PESQUISA “ANTROPOLOGIA DA PESSOA: OS PROCESSOS DE INDIVIDUALIZAÇÃO NA CULTURA CONTEMPORÂNEA". Reunião de Antropologia do Mercosul, 4., 2001. CRARY, J. Modernizing vision. In: FOSTER, H. (Ed). Vision and visuality: discussions on contemporary culture - 2. 1.ed. New York: The New Press, 
1999a. p. 29-49.

. Techniques of the observer: on vision and modernity in the nineteenth century. 9.ed. London : MIT Press, 1999b.

. A visão que se desprende: Manet e o observador atento no fim do século XIX. In: CHARNEY, L.; SCHWARTZ, V. (Org.). O cinema e a invenção da vida moderna. 1.ed. São Paulo: Coseac \& Naify, 2001. p. 81114.

ELIAS, N. A civilização como transformação do comportamento humano. In: O processo civilizador. 2.ed. Rio de Janeiro: Jorge Zahar Editor, 1994. v.1

FOUCAULT, M. O nascimento da clínica. 5.ed. Rio de Janeiro: Forense Universitária, 1998.

Vozes, 1999.

. Vigiar e punir: história da violência nas prisões. 19.ed. Petrópolis:

GUSDORF, G. Domaine germanique. In: . Le savoir romantique de la nature. Paris: Payot, 1985. p. 69-104.

PALL MALL GAZETTE. Occasional Notes. London, n. 20, Mar. 1896. p. 2. PORTER, R. The greatest benefit to mankind: a medical history of humanity. 1.ed. New York : W.W.Norton \& Company, 1997.

SIBILIA, P. O homem pós-orgânico: corpo, subjetividade e tecnologias digitais. 1.ed. Rio de Janeiro: Relume Dumará, 2002.

STURKEN, M.; CARTWRIGHT, L. Practices of looking: an introduction to visual culture. 1.ed. New York: Oxford University Press, 2001.

TAYLOR, C. As fontes do self: a construção da identidade moderna. 1.ed. São Paulo: Edições Loyola, 1997.

\section{NOTAS}

1 Este artigo é uma segunda versão do trabalho intitulado "O corpo transparente: um panóptico invertido? Considerações sobre as tecnologias de imagem nas reconfigurações da Pessoa contemporânea", apresentado na XXVI Reunião da ANPOCS, no GT 13: Pessoa e Corpo, em Caxambu, 2002.

2 Médica. Mestre e doutoranda em Saúde Coletiva, na área de Ciências Humanas e Saúde, do Programa de Pós-graduação em Saúde Coletiva do IMS/UERJ.

3 A tradução dos textos citados é de nossa autoria, salvo menção expressa.

4 Utilizamos o termo media como plural de medium, com o sentido de "forma intermediária através da qual a mensagem passa (...) tecnologia específica através das quais as mensagens são transmitidas" (Sturken \& Cartwright, 2001, p. 359). 
5 Utilizamos "referente" no sentido que tem para a semiótica. O termo diz respeito ao objeto em si, como oposto à sua representação. Esta designação é útil para a distinção entre "representação" - referida a objetos existentes no mundo real -, e "simulação": a cópia que não tem equivalente real (Sturken \& Cartwright, 2001, p. 364).

$6 \mathrm{O}$ primeiro destes foi o thaumatrope, popularizado em Londres, em 1825, pelo dr. John Paris. Consistia em um disco com imagens complementares em cada face que, quando girado rapidamente, produzia uma superposição das duas. O phenakistiscope foi construído em torno de 1830, por Joseph Plateau. Consistia em um disco, dividido em oito ou dezesseis segmentos iguais, cada um contendo uma pequena fenda e uma figura em posições seqüenciadas de um movimento. A face com figuras era virada para o espelho e o observador ficava imóvel em frente dele, com o dispositivo diante de um dos olhos. A seguir girava-se o disco. Quando cada fenda passava diante do olho, via-se uma das figuras. Em virtude da persistência retiniana, a imagem parecia executar o movimento. O zootrópio, inventado em 1834 por William G. Horner, tinha uma estrutura semelhante. O estroboscópio, usado até nossos dias, foi inventado em 1834 por Stampfer, um matemático alemão. O diorama ganhou sua forma definitiva nas mãos de Louis J. M. Daguerre, em torno de 1820. A audiência ficava sentada em uma plataforma circular que girava lentamente, permitindo que os espectadores vissem cenas diferentes e efeitos luminosos cambiantes (Crary, 1999b, p. 109).

7 O invento original, "modelo Wheatstone", funcionava com um observador com os olhos diretamente voltados para a frente, onde havia dois espelhos planos colocados em ângulo de $90^{\circ}$. As imagens a serem olhadas eram colocadas em fendas, uma de cada lado do sujeito, completamente separadas entre si. Outros modelos surgiram depois, mas o original deixava bem clara a natureza da imagem obtida pelo espectador (Crary, 1999b, p. 129). Havia, em comum com os outros dispositivos, o fato de que a imagem se fundia dentro do observador, indicando uma mesma estrutura conceitual. A diferença básica consistia em que, na produção da imagem estereoscópica, a ilusão não era a de movimento, e sim a simulação de profundidade, visualizando-se figuras em planos distintos. A diferença entre o estereoscópio e os outros dispositivos era, portanto, que a ilusão por ele produzida era a de tridimensionalidade, enquanto a dos outros era a de movimento em um plano bidimensional.

8 Para uma discussão sobre o papel da perspectiva na construção dos códigos visuais, cf. Sturken \& Cartwright (2001, p. 113 et passim.).

9 Para analisar tecidos mortos, destacados do corpo, pode-se incluir a peça anatômica em parafina para depois cortá-la em lâminas finíssimas com micrótomo - aparelho inventado para esta finalidade - e em seguida usar diversas técnicas com corantes químicos para destacar as células.

10 Cartwright associa os modos microscópicos de representação e convenção aos códigos visuais vigentes no movimento modernista, em especial cubista, desta época (Cartwright, 1995, p. xiv, p. 99-103). Uma característica central do cubismo consistia em uma visão bidimensional, simultânea e fragmentada de diversos pontos de vista, que desafiava frontalmente não só a perspectiva como também as premissas culturais nas quais esta se inscrevia. As imagens microscópicas de estruturas do organismo apresentam-se totalmente abstratas, não podendo ser aferidas pelo olho nu. Na realidade, a possibilidade de visão microscópica existia desde o século XVII, quando foi inventado o microscópio de lente única, pelo holandês Anton van Löeuwenhoek. O ponto em discussão aqui é a apropriação da microscopia pelo cinema e seu papel na construção do olhar modernista. Para uma discussão aprofundada a este respeito, cf. Cartwright (1995, p. 81 et passim.).

11 O termo hiper-real foi cunhado por Baudrillard para designar "um mundo no qual os códigos de realidade são usados para simular a realidade em casos nos quais não há referente no mundo 
real" (Sturken \& Cartwright, 2001, p. 357).

12 No Renascimento, um exemplo é o realismo das pranchas anatômicas de Vesalius.

13 Barthélemy Coclès, em 1533, publicou o livro Physiognomonia (Sturken \& Cartwright, 2001, p. 282).

14 Wilhelm Konrad Röentgen (1845-1923) era professor de Física em Würzburg e em 1901 recebeu o prêmio Nobel de Física por seu trabalho.

15 A nota publicada no Pall Mall Gazette, em março de 1896, é exemplar de um dos tipos de reação provocada: "Estamos enojados com os raios Röntgen [sic]. Diz-se agora, esperamos que, inveridicamente, que o sr. Edison descobriu uma substância - seu nome repulsivo é tungstato de cálcio - que potencializa (o que quer que isto queira dizer) os ditos raios. A conseqüência disto parece ser que se podem ver os ossos das outras pessoas a olho nu, e também ver através de oito polegadas de madeira sólida. Não há necessidade de nos estendermos sobre a revoltante indecência disto. Mas estamos chamando seriamente a atenção do governo para o fato que, no momento em que o tungstato de cálcio se tornar de uso geral, haverá necessidade de legislação restritiva do tipo mais severo possível. Olhar através da porta de uma pessoa é um crime tão sério quanto falsificar seu nome, e fazê-lo sem autorização deveria realmente ser punido com uma longa estadia de trabalhos forçados na prisão. Da mesma maneira, olhar os ossos de outra pessoa sem permissão deveria ser encarado como uma forma grave de atentado ao pudor. Mas mesmo a legislação mais severa só poderia, no máximo, controlar as práticas mais revoltantes. Talvez a melhor coisa seria todas as nações civilizadas fazerem um pacto: queimar todos os trabalhos sobre os raios Röntgen, executar todos os descobridores, juntar (isolar) todo o tungstato do mundo, e afundá-lo no meio do Atlântico. Deixem os cetáceos, e não nós, contemplarem os ossos uns dos outros" (Pall Mall Gazette, 1896).

16 Tais como ausculta, palpação e percussão do corpo do doente, procedimentos que demandam uso da audição e do tato do médico. Até o surgimento da radiografia, a visão possibilitava apenas o exame ectoscópico do doente. Esses recursos continuam sendo utilizados nos dias atuais. O ponto aqui ressaltado é a construção de uma nova possibilidade de utilização da visão, através do uso de radiografia.

17 Fantasmagoria foi um tipo específico de apresentação de lanterna mágica, no final do século XVIII e início do XIX, que usava retroprojeção para que a audiência não visse as lanternas (Crary, 1999b, p. 132).

18 Camera obscura é um dispositivo ótico que consiste em uma caixa fechada, de tamanho variável, com o interior escuro, na qual é aberto um pequeno furo que permite a passagem de um feixe luminoso. No lado oposto à abertura surge projetada uma imagem invertida do objeto ou paisagem que se encontra no exterior, diante do furo. Durante aproximadamente dois séculos - de fins do século XVI a fins do XVIII - a camera obscura esteve muito em voga, tendo caído em desuso no início do século XIX (Cf. Chazan, 2001).

19 Utilizamos "cultura leiga" em contraposição a "cultura médica".

20 Sobre estas técnicas, a quimografia, a cronofototografia e outras, cf. Cartwright (1995, p. 17 et passim.).

21 Thomas Alva Edison patenteara um aparelho - o kinetoscope - em 31/08/1887, que permitia a visualização, por uma pessoa de cada vez, de imagens fotográficas seriadas de movimento passadas em sucessão rápida, o que produzia uma ilusão similar à do cinematógrafo.

$22 \mathrm{Na}$ realidade, apenas a possibilidade de obtê-la já introduz uma reconfiguração na construção 
social do corpo.

23 A tecnologia digital consiste em informações contidas em bits codificados matematicamente, cada um representando um valor distinto, separados entre si, o que permite manipulação e cópia idêntica absolutamente imediatas. A digitalização de dados rompe a noção de "original" e "cópia" (Sturken \& Cartwright, 2001, p. 353).

24 Sigla para Positron Emission Tomography.

25 A tecnologia analógica é a representação de dados através de propriedades físicas que expressam valor ao longo de uma escala contínua, como p. ex. a fotografia, disco de vinil, fitas de gravador, nos quais os altos e baixos, claros e escuros, são medidos em uma escala de intensidade gradativa (Sturken \& Cartwright, 2001, p. 349).

26 Alphonse Bertillon, no século XIX, criou um sistema de medição para identificar os "tipos corporais criminais". Utilizou fotos de frente e perfil como meio de determinar características corporais que pudessem ser associadas à criminalidade. Este sistema é até hoje utilizado na identificação criminal (mug shots). Na mesma época, Cesare Lombroso acreditava também que a criminalidade tinha raízes biológicas e que se podiam estabelecer quais traços corporais eram indicativos de uma "constituição criminosa" (Sturken \& Cartwright, 2001, p. 95).

27 A discussão acerca do consumismo é infinitamente mais complexa e escapa ao âmbito deste trabalho. Para a discussão sobre a construção do desejo articulada com a cultura visual, na sociedade de consumo, cf. Sturken \& Cartwright (2001, p. 189-236). Para uma melhor compreensão acerca do consumismo moderno, cf. Campbell (2001).

28 Esta noção está presente também na criogenia, onde se pode conservar apenas o cérebro visando à reconstituição da pessoa no futuro. Em uma inflexão diferente, mas partindo do mesmo pressuposto que equaliza a Pessoa ao cérebro, a cibernética pretende fazer o download do cérebro em um programa, tornando possível atingir a imortalidade (Sibilia, 2002, p. 55).

29 O filme Gattaca, de Andrew Niccol (USA, 1997), fornece um bom exemplo de problematização dos sistemas de identificação baseados no código genético. Além da ficção científica, os modernos métodos policiais estão já há algum tempo utilizando a identificação genética como procedimento para solução de crimes. 


\section{ABSTRACT}

The Transparent Body and the Expanded Panoptic: Remarks on Imaging Technologies and Reconfigurations of the Contemporary Persona

This article discusses how imaging technologies - especially those applied to medicine over the course of the $20^{\text {th }}$ century - interact with visual culture, and how, based on this dynamic articulation, the body and persona (among other aspects) are reshaped. As with other human activities, visuality is informed and shaped by the socio-cultural and historical context in which it is experienced. In the final decades of the $20^{\text {th }}$ century, with the dissemination of computer technology, new paradigms emerged that were informed by the digitalization of information and images. Together with visual technologies, other scientific fields, especially genetics, have played a significant role in new social constructions. The article therefore touches on them in passing as an attempt to expose part of the complex situation in which the body and persona are reshaped.

Keywords: Imaging technologies; body; persona; visual culture; digitalization.

Recebido em: 17/09/2002.

Aprovado em: 23/03/2003. 